\title{
Prenatal maternal stress associated with ADHD and autistic traits in early childhood
}

\author{
Angelica Ronald ${ }^{1 *}$, Craig E. Pennell ${ }^{2}$ and Andrew J. O. Whitehouse ${ }^{3}$ \\ 1 Department of Psychological Sciences, Centre for Brain and Cognitive Development, Birkbeck, University of London, London, UK \\ 2 School of Women's and Infants' Health, University of Western Australia, Perth, WA, Australia \\ 3 Telethon Institute for Child Health Research, Centre for Child Health Research, University of Western Australia, Perth, WA, Australia
}

\section{Edited by:}

Frederic Dick,

University of California San Diego, USA

\section{Reviewed by:}

Frances Rice,

University College London, UK

Angela Michelle Reiersen, Washington

University School of Medicine, USA

*Correspondence:

Angelica Ronald, Department of Psychological Sciences, Centre for Brain and Cognitive Development, Birkbeck, Malet Street, London WC1E 7HX, UK.

e-mail:a.ronald@bbk.ac.uk
Research suggests that offspring of mothers who experience high levels of stress during pregnancy are more likely to have problems in neurobehavioral development. There is preliminary evidence that prenatal maternal stress (PNMS) is a risk factor for both autism and attention deficit hyperactivity disorder (ADHD), however most studies do not control for confounding factors and no study has investigated PNMS as a risk factor for behaviors characteristic of these disorders in early childhood. A population cohort of 2900 pregnant women were recruited before their 18th week of pregnancy and investigated prospectively. Maternal experience of stressful life events was assessed during pregnancy. When offspring were age 2 years, mothers completed the child behavior checklist. Multiple regression showed that maternal stressful events during pregnancy significantly predicted $A D H D$ behaviors in offspring, after controlling for autistic traits and other confounding variables, in both males $(p=0.03)$ and females $(p=0.01)$. Similarly, stressful events during pregnancy significantly predicted autistic traits in the offspring after controlling for ADHD behaviors and confounding variables, in males only $(p=0.04)$. In conclusion, this study suggests that PNMS, in the form of typical stressful life events such as divorce or a residential move, show a small but significant association with both autistic traits and ADHD behaviors independently, in offspring at age 2 years, after controlling for multiple antenatal, obstetric, postnatal, and sociodemographic covariates. This finding supports future research using epigenetic, cross-fostering, and gene-environment interaction designs to identify the causal processes underlying this association.

Keywords: prenatal, stress, ADHD, autism, autistic traits, Raine Study

\section{INTRODUCTION}

Research suggests that offspring of mothers who experience high levels of stress during pregnancy are more likely to have problems in neurobehavioral development. A large number of prospective studies have shown that prenatal maternal stress (PNMS) increases risk in the offspring for childhood behavior and emotional problems, language delay, cognitive problems, mixed handedness, and later onset disorders such as schizophrenia (Van den Bergh et al., 2005; Rice et al., 2007; Talge et al., 2007; Robinson et al., 2008). Animal models, particularly with rodents and non-human primates, have also demonstrated that induced prenatal stress on pregnant females is associated with behavioral differences in offspring (Beydoun and Saftlas, 2008; Boksa, 2010).

Autistic spectrum disorder (ASD) and attention deficit hyperactivity disorder (ADHD) are both lifelong neurodevelopmental conditions that begin in early childhood and affect males more often than females. Four studies have explored the association between PNMS and autism. Family discord (Ward, 1990), stressful life events (recalled retrospectively; Beversdorf et al., 2005), and hurricanes and tropical storms (Kinney et al., 2008) during pregnancy have

Abbreviations: ADHD, attention deficit hyperactivity disorder; CBCL, child behavior checklist; PDP, pervasive developmental problems; PNMS, prenatal maternal stress. all been shown to be associated with elevated risk for autism in the resulting offspring, but maternal bereavement, assessed in a large population-based cohort, did not show such an association (Li et al., 2009). All these studies focused on children with autistic disorder and did not include children with autistic spectrum conditions (e.g., Asperger's Syndrome) or subclinical behaviors. Further research utilizing broader measures of autistic-like traits and prospectively collected data on relatively common stressors during pregnancy could facilitate greater understanding of PNMS as a possible risk factor for the autism phenotype. Studies often do not control for postnatal factors that PNMS might be associated with, such as maternal postnatal depression. Furthermore, no consideration has been given to comorbid disorders often shown in individuals with autism, such as ADHD, which may be driving these reported associations.

Research exploring an association between PNMS and ADHD includes four prospective longitudinal studies. Three of these studies have reported significant associations of antenatal anxiety or perceived stress during pregnancy with ADHD symptoms in school-aged children aged 4-9 from community samples (O'Connor et al., 2002, 2003; Van den Bergh and Marcoen, 2004; Rodriguez and Bohlin, 2005) and one reported an association of psychosocial adversity, which included stressful life events, with offspring ADHD behaviors (Laucht et al., 2000). Two studies on 
6- to 12-year-old children with diagnosed ADHD that relied on maternal retrospective recall reported that maternal emotional stress was significantly associated with offspring ADHD diagnosis (McIntosh et al., 1995) and that number of stressful life events during the mother's pregnancy was associated with the severity of the offspring's ADHD symptoms (Grizenko et al., 2008). In addition, positive life events and marital satisfaction were found to be lower during pregnancy in women who had children with ADHD versus controls (Lee et al., 2006). Finally, using a crossfostering design, a significant association between ADHD symptoms in offspring and maternal stress was reported in biologically related mothers but not in a group of non-biologically related mothers, which led the authors to suggest that the association between PNMS and ADHD may be due to inherited factors (Rice et al., 2010).

Although their core diagnostic symptoms do not explicitly overlap, high levels of comorbidity between ASD and ADHD have been reported. For example, a population-derived sample that used structured assessments found that $28 \%$ of their sample with ASD also had ADHD (Simonoff et al., 2008). Autistic traits and ADHD behaviors are positively correlated in the general population (Constantino et al., 2003; Reiersen et al., 2008; Ronald et al., 2008, 2010), and twin studies suggest that ADHD behaviors and autistic traits share some genetic and environmental influences (Constantino et al., 2003; Reiersen et al., 2008; Ronald et al., 2008, 2010). The identification of risk factors for ASD and ADHD is an important goal for child mental health research and for developmental psychology.

The first aim of this study was to extend the literature reviewed above to explore the association between PNMS and autistic traits and ADHD behaviors in 2-year-olds, using a prospective longitudinal sample, a broad measure of common stressors, and including multiple confounders. Because both ADHD and autism show a male predominance, analyses were split by gender. The second aim was to explore whether PNMS is associated with both autistic traits and ADHD behaviors independently, or whether PNMS is part of a common etiological pathway that could help explain the high co-occurrence of autistic traits and ADHD behaviors.

\section{MATERIALS AND METHODS}

The Western Australia Pregnancy Cohort (Raine) Study is a longitudinal study of women and their children recruited between 16 and 18 weeks of pregnancy from the public antenatal clinic at King Edward Memorial Hospital (KEMH) or surrounding private clinics in Perth. Approximately 100 women per month were enrolled from August 1989 to April 1992, with a final sample of 2900 pregnancies. The inclusion criteria were English language skills sufficient to understand the study demands, an expectation to deliver at KEMH, and an intention to remain in Western Australia to enable future follow-up of their child (Newnham et al., 1993). From the 2900 pregnancies recruited, 2868 live born children have been comprehensively phenotyped over the past 20 years. Children with intellectual disability with a known cause were excluded from the current study $(n=29)$. Participant recruitment and all follow-ups of the study families were approved by the Human Ethics Committee at KEMH and/or Princess Margaret Hospital for Children in Perth.

\section{OUTCOME VARIABLES}

Child behavior was assessed at the 2-year follow-up using the child behavior checklist (CBCL) for Ages 11/2-5, an empirically validated parent-report measure (Achenbach et al., 1987). Caregivers were provided with 99 statements regarding their child's behavior and asked to respond on a three-point Likert scale as to whether a particular statement was very true (score of 2), somewhat true (score of 1 ) or not true (score of 0 ). The ADHD and pervasive developmental problems (PDP) scales are based upon DSM-IV (American Psychiatric Association, 1994) symptom categories for ADHD and Autistic Disorder, respectively. The ADHD scale consists of six statements assessing a child's inattentive and hyperactive behavior (e.g., "Cannot concentrate, cannot pay attention for long," "Cannot sit still, restless, or hyperactive"), and the PDP scale includes 13 statements regarding the child's social-communicative (e.g., "Avoids looking others in the eye") and repetitive behaviors/ routines (e.g., "Disturbed by any change in routine"). Responses to items within each scale were summed to provide a total score, with higher scores denoting more ADHD symptoms (range: 0-12) or ASD-like traits (range: 0-26). Scores from cases with missing data on up to half of the items on a particular scale were prorated to yield a score out of the maximum for that scale. Data were coded as missing when more than half of the items on a particular scale were not answered.

The PDP preschool scale has an acceptable test-retest reliability of 0.86 and high sensitivity for detecting children with ADOS-G classification of autism ( $80 \%$ ) but modest specificity (42\%; Sikora et al., 2008). The ADHD CBCL preschool scale has been shown to have test-retest reliability of 0.74 and an odds ratio of 4 , that is, children who score in the clinical range have four times greater odds of being from a referred sample than those that do not score in the clinical range (Achenbach and Rescorla, 2000). The internal consistency in the Raine cohort was modest for the PDP Scale (Cronbach's $\alpha=0.60$ ) and adequate for the ADHD scale (Cronbach's $\alpha=0.77$ ).

The PDP scale can be further divided into two subscales, relating to social and non-social autistic-like traits (Ronald et al., 2010). From the CBCL PDP scale, six items related to social behaviors (e.g., paucity of social interaction, not answering to name) and five items to non-social behaviors (e.g., preference for sameness, repetitive body motions), with a further two PDP items excluded because they do not clearly relate to either category ("speech problems" and "strange behaviors"). Within each subscale, individual item scores were tallied to provide an overall index ranging from 0 to 12 (social subscale) or 0 to 10 (non-social subscale), with higher scores indicating greater severity of traits. The prorating procedure described above was applied to these subscales as well. The internal consistency for the social (Cronbach's $\alpha=0.41$ ) and non-social subscales (Cronbach's $\alpha=0.50$ ) in the sample were modest. Both scales were positively skewed and were normalized using cumulative frequency rank-transformation.

\section{PREDICTOR VARIABLES}

The predictor variable was the number of stress events experienced by mothers during pregnancy. Mothers were asked at 18 and 34 weeks gestation whether or not they had experienced any of 10 major life stress events selected from a broader life stress inventory 
(Tennant and Andrews, 1976): pregnancy problems, death of a close friend or relative, separation or divorce, marital problems, problems with children, job loss (involuntary), partner's job loss (involuntary), money problems, residential move, or other stressful event. The questionnaire at 18 weeks gestation asked whether any of the events had been experienced since becoming pregnant and, in the 34-week gestation questionnaire, whether any of the events had been experienced within the last 4 months, ensuring that the same event was not counted twice. Stress events recorded at 18 and 34 weeks were tallied to provide on overall index of maternal stress. This approach was taken because the type of stressful events that were asked about do not have obvious temporal boundaries (Talge et al., 2007) and therefore an overall stress events score was considered most appropriate.

The influence of a range of covariates known to have an influence on ADHD and autistic symptoms was also considered. These variables included: (1) sociodemographic factors recorded at 18 weeks pregnancy (maternal age at conception, maternal education, family income, and the presence of the biological father in the family home); (2) antenatal variables recorded at 34 weeks pregnancy (maternal smoking during pregnancy: no smoking; 1-10 cigarettes per day; or 11+ cigarettes per day; maternal alcohol consumption during pregnancy: no alcohol consumed; consumed alcohol once per week or less; consumed alcohol several times per week or daily); and (3) obstetric variables recorded at birth (parity; gestational age; child's sex; proportion of optimal birth weight, a measure of the appropriateness of fetal growth (Blair et al., 2005); and Apgar scores at $5 \mathrm{~min}$ ). Postpartum mood disturbance was measured using an index of 16 postnatal feelings on the Blues Questionnaire, completed by mothers after birth and while still in hospital. These 16 items were a summation of the 22 item Blues Scale (Kennerley and Gath, 1989), a robust and valid measure of "baby blues" symptoms immediately postpartum (Henshaw, 2003).

\section{SAMPLE ATTRITION}

Complete PNMS data were available for mothers relating to 2575 children. CBCL data at age 2 years were obtained on 1746 of these participants, a longitudinal follow-up rate of $67.8 \%$. Complete PDP and ADHD datasets were available for $94.2 \%(n=1644)$ and $97.9 \%(n=1710)$ of the sample, respectively. The mean age of the children at CBCL data collection was 2.14 years $(\mathrm{SD}=0.15$; range $=1.92-3.29)$, with $96.2 \%(n=1680)$ of checklists completed between the children's second and third birthdays.

Independent samples $t$-tests and chi-square analyses found that the 829 children who did not participate in the 2 -year cohort review differed somewhat to the families who participated at the 2-yearold offspring data collection. For example, children in families who withdrew had younger gestational age at birth (withdrew: $M=39.12, \mathrm{SD}=2.46$; remained: $M=39.38, \mathrm{SD}=2.33 ; p<0.05)$, had mothers who were younger at conception (withdrew: $M=26.17$, $\mathrm{SD}=6.14$; remained: $M=28.06$ years, $\mathrm{SD}=5.69 ; p<0.01)$, and experienced more stress events during pregnancy (withdrew: $M=2.27, \mathrm{SD}=2.08$; remained: $M=1.83, \mathrm{SD}=1.81 ; p<0.01$ ), Therefore a modest degree of bias is present in the sample due to attrition, but overall the sample remains representative of the general population (Kendall, 2003).

\section{STATISTICAL ANALYSES}

Multivariate linear regression analyses using the block enter method were employed. Missing data were deleted pairwise. Analyses were conducted separately for males $(n=913)$ and females $(n=833)$. A sample size of 800 is robust to detect an effect size of 0.05 with $99 \%$ power and $95 \%$ confidence and 15 predictors.

\section{RESULTS}

Table 1 presents the frequency characteristics of the cohort with maternal stress event information during pregnancy and CBCL data at age 2 years. Figures 1A,B show the distribution of the PDP and ADHD scores for these participants, respectively. Continuous variables were normally distributed (Kolmogorov-Smirnov test of normality, $p>0.05$ ), except for the number of stress events during pregnancy and during the first year of life, which were rank transformed using cumulative frequency $z$-scores. $Z$-scores of this variable were used for all analyses. Independent $t$-tests and chi-square analyses found a gender difference between one predictor variable only, with fathers of girls more likely to be absent from the family home during pregnancy $(p=0.01$; all other comparisons, $p>0.10)$. Gender differences in PDP and ADHD scales were then examined. PDP scores were positively skewed and were rank transformed using cumulative frequency $z$-scores. Once again, $z$-scores for this variable were used for all analyses. Independent $t$-tests revealed that males $(M=5.97, \mathrm{SD}=2.72$, range $=0-12$ ) had significantly higher scores on the ADHD scale than females $(M=5.6, \mathrm{SD}=2.7$, range $=0-12, p=0.01)$. There was a trend in the same direction for PDP scores (untransformed scores for males: $M=3.17, \mathrm{SD}=2.52$, range $=0-15$; females: $M=2.97, \mathrm{SD}=2.35$, range $=0-16)$, however the difference did not reach statistical significance (comparison for transformed scores, $p=0.14$ ).

Bivariate analyses identified a significant positive correlation between the number of stress events during pregnancy and the PDP and ADHD scales in male offspring ( $r=0.17$ and 0.15 , respectively, both $p<0.01)$. For females, stress events during pregnancy positively correlated with the ADHD subscale $(r=0.14, p<0.01)$, but not with the PDP scale $(r=0.07$, n.s.).

Univariate linear regression analyses examined the relation between the individual confounding variables and PDP and ADHD scores. All the variables presented in Tables 2 and 3 showed a significant association with either the PDP or ADHD scale. No associations were found with either PDP or ADHD scales at age 2 years for the following variables: maternal country of birth, moderate maternal smoking (1-10 cigarettes per day) and alcohol intake (once per week or less) during pregnancy, gestational age at birth, proportion of optimal birthweight, or Apgar scores at $5 \mathrm{~min}$. These variables were excluded from further analyses.

Table 2 presents the results of the multivariate linear regression analyses examining the effect of the predictor variable and covariates on PDP scores. There was a significant, positive association between the number of maternal stress events experienced during pregnancy and PDP scores in male offspring $(p<0.01)$, but not female offspring $(p=0.79)$, after controlling for all the confounding variables. The inclusion of PNMS in the second block of the regression analysis for males significantly improved the model, 
Table 1 | Frequency distribution of the predictor variable ( $\boldsymbol{N}$ stress events during pregnancy) and covariates (other factors) for male and female offspring.

\begin{tabular}{|c|c|c|c|c|c|c|}
\hline \multirow[t]{2}{*}{ Continuous variables } & \multicolumn{3}{|c|}{ Males } & \multicolumn{3}{|c|}{ Females } \\
\hline & $n$ & $M$ & SD & $n$ & $M$ & SD \\
\hline $\begin{array}{l}\text { Maternal age at } \\
\text { conception (years) }\end{array}$ & 913 & 28.15 & 5.63 & 833 & 27.96 & 5.75 \\
\hline $\begin{array}{l}\text { Gestational age at } \\
\text { delivery (weeks) }\end{array}$ & 888 & 39.40 & 2.62 & 808 & 39.37 & 1.98 \\
\hline $\begin{array}{l}\text { Nstress events } \\
\text { during pregnancy }\end{array}$ & 913 & 1.80 & 1.80 & 833 & 1.87 & 1.83 \\
\hline $\begin{array}{l}\text { Proportion of optimal } \\
\text { birth weight (\%) }\end{array}$ & 912 & 97.52 & 12.71 & 829 & 97.31 & 12.44 \\
\hline 5 min Apgar scores & 913 & 9.10 & 3.06 & 831 & 9.05 & 0.71 \\
\hline Baby blues symptoms & 786 & 2.96 & 2.95 & 729 & 2.93 & 3.05 \\
\hline Categorical variables & $N$ & $n$ & $\%$ & $N$ & $n$ & $\%$ \\
\hline $\begin{array}{l}\text { Maternal education } \\
\text { at pregnancy }\end{array}$ & 913 & & & 833 & & \\
\hline $\begin{array}{l}\text { Completed secondary } \\
\text { school }\end{array}$ & & 393 & 43.00 & & 349 & 41.90 \\
\hline $\begin{array}{l}\text { Did not complete } \\
\text { secondary school }\end{array}$ & & 520 & 57.00 & & 484 & 58.10 \\
\hline Smoking in pregnancy & 913 & & & 833 & & \\
\hline None & & 714 & 78.20 & & 637 & 76.50 \\
\hline $1-10$ cigarettes daily & & 99 & 10.80 & & 100 & 12.00 \\
\hline $11+$ cigarettes daily & & 100 & 11.00 & & 96 & 11.50 \\
\hline $\begin{array}{l}\text { Alcohol consumption } \\
\text { during pregnancy }\end{array}$ & 913 & & & 833 & & \\
\hline None & & 534 & 58.50 & & 519 & 62.30 \\
\hline Once a week or less & & 327 & 35.80 & & 264 & 31.70 \\
\hline $\begin{array}{l}\text { Several times a } \\
\text { week or more }\end{array}$ & & 52 & 5.70 & & 50 & 6.00 \\
\hline $\begin{array}{l}\text { Family income during } \\
\text { pregnancy }\end{array}$ & 888 & & & 793 & & \\
\hline$\geq \$ 24,000$ & & 550 & 61.90 & & 481 & 60.70 \\
\hline$<\$ 24,000$ & & 338 & 38.10 & & 312 & 39.30 \\
\hline $\begin{array}{l}\text { Biological father living with } \\
\text { family during pregnancy }\end{array}$ & 904 & & & 829 & & \\
\hline Yes & & 832 & 92.00 & & 733 & 88.40 \\
\hline No & & 72 & 8.00 & & 96 & 11.60 \\
\hline Parity & 913 & & & 833 & & \\
\hline 0 & & 416 & 45.60 & & 418 & 50.20 \\
\hline 1 & & 287 & 31.40 & & 235 & 28.20 \\
\hline$>1$ & & 210 & 23.00 & & 180 & 21.60 \\
\hline
\end{tabular}

accounting for an additional $1 \%$ of the variation in PDP scores at age 2 years. Of the potential confounders included in the models, child ADHD scores were positively associated with child PDP scores in both genders, while maternal baby blues symptoms were associated with higher PDP scores in females only. Among males, child's age positively predicted PDP scores, while maternal consumption of alcohol several times a week or more during pregnancy was negatively associated with PDP scores.

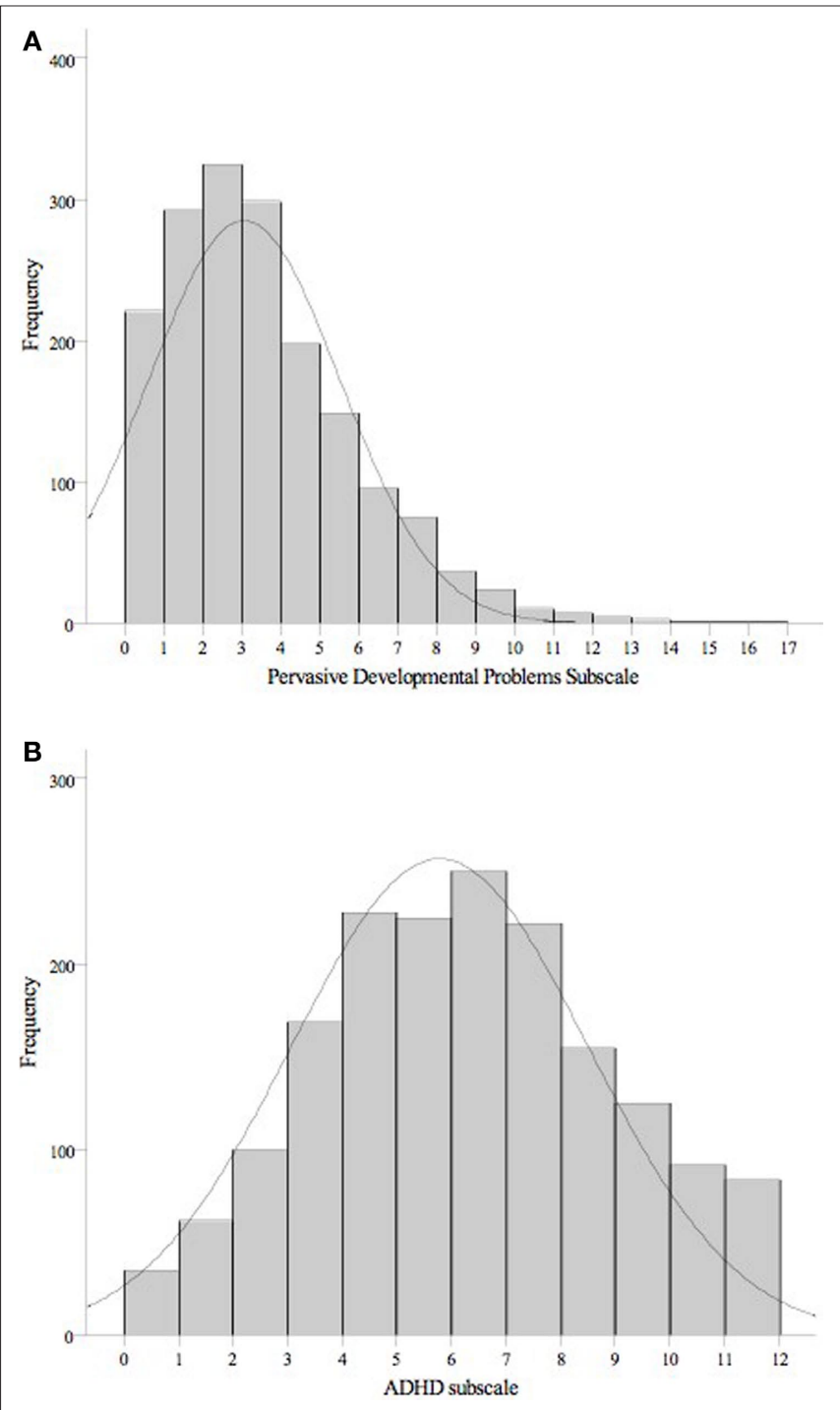

FIGURE 1 | Histograms showing the distribution of scores on the autistic trait (A) and ADHD behavior (B) subscales for the 1746 two-year-olds.

In additional analyses, the association between the number of stress events during pregnancy and scores on PDP "social" and "non-social" subscales at age 2 years was assessed separately. The number of stress events was positively correlated with the social and non-social subscales in males (social: $r=0.11$; non-social: $r=0.13$; both $p<0.001$ ) but not females (social: $r=0.03$; nonsocial: $r=0.06$; both $p>0.05$ ). Multivariate linear regression for males found a significant effect of stress events on scores for the non-social scale $(p=0.01)$ but not the social scale $(p=0.16)$.

Multivariate linear regression models investigating the effect of PNMS on ADHD scores at age 2 years (Table 3 ) identified a significant positive association in males $(p=0.03)$ and females $(p<0.01)$. PNMS accounted for $1 \%$ of the variance in ADHD scores at age 2 years in both genders, after controlling for multiple confounds, including PDP scores. Child scores on the PDP subscale positively predicted child ADHD scores in males and females. Among males, maternal smoking of $11+$ cigarettes per day during 
Table 2 | Multivariate linear regression model for autistic trait scores at age 2 years.

\begin{tabular}{|c|c|c|c|c|}
\hline & \multicolumn{2}{|c|}{ Males } & \multicolumn{2}{|c|}{ Females } \\
\hline & $\beta$ & SE B & $\beta$ & SE B \\
\hline \multicolumn{5}{|l|}{ STEP 1: COVARIATES } \\
\hline Maternal age at conception & -0.05 & 0.01 & -0.06 & 0.01 \\
\hline $\begin{array}{l}\text { Mother did not complete } \\
\text { secondary school }\end{array}$ & -0.04 & 0.06 & 0.02 & 0.06 \\
\hline $\begin{array}{l}\text { Father not present } \\
\text { in family home }\end{array}$ & 0.02 & 0.09 & -0.03 & 0.09 \\
\hline Family income $<\$ A \cup D 24,000$ & 0.00 & 0.06 & 0.01 & 0.07 \\
\hline \multicolumn{5}{|c|}{ MATERNAL INTAKE DURING PREGNANCY } \\
\hline $\begin{array}{l}\text { Alcohol } \geq \text { several } \\
\text { times per week }\end{array}$ & $-0.07^{*}$ & 0.13 & -0.04 & 0.13 \\
\hline $\begin{array}{l}\text { Smoking } 11+\text { cigarettes } \\
\text { per day }\end{array}$ & 0.00 & 0.09 & 0.01 & 0.09 \\
\hline \multicolumn{5}{|l|}{ PARITY } \\
\hline 1 & 0.00 & 0.07 & 0.03 & 0.07 \\
\hline$>1$ & -0.02 & 0.08 & 0.00 & 0.08 \\
\hline Baby blues symptoms & 0.06 & 0.01 & $0.11 * *$ & 0.01 \\
\hline $\begin{array}{l}\text { Child's age at } 2 \text { year } \\
\text { assessment }\end{array}$ & $0.07^{*}$ & 0.18 & 0.06 & 0.19 \\
\hline ADHD score & $0.35^{* *}$ & 0.01 & $0.33^{*}$ & 0.01 \\
\hline$R^{2}$ for step 1 & \multicolumn{2}{|c|}{$0.17^{* *}$} & \multicolumn{2}{|c|}{$0.15^{* *}$} \\
\hline \multicolumn{5}{|l|}{ STEP 2: PREDICTORS } \\
\hline $\begin{array}{l}N \text { stress events } \\
\text { during pregnancy }\end{array}$ & $0.10 * *$ & 0.04 & -0.01 & 0.04 \\
\hline$\Delta R^{2}$ for step 2 & \multicolumn{2}{|c|}{$0.01^{* *}$} & \multicolumn{2}{|c|}{$<0.01$} \\
\hline Change in $F_{\text {model }}$ & \multicolumn{2}{|c|}{$9.22^{* *}$} & \multicolumn{2}{|c|}{0.07} \\
\hline
\end{tabular}

Moderate maternal smoking and alcohol intake during pregnancy, gestational age at birth, proportion of optimal birthweight, Apgar scores (5 min) and maternal country of birth were excluded from the analyses because they did not show a significant univariate association with PDP or ADHD scales for either sex. PDP, pervasive developmental problems (autistic traits) subscale. $A D H D$, attention deficit hyperactivity subscale. ${ }^{*} p<0.05 ;{ }^{* *} p<0.01$.

pregnancy and maternal baby blues symptoms related to higher scores on the ADHD scale, while the child's age at CBCL assessment and a parity of greater than one was associated with lower ADHD scores.

Attention deficit hyperactivity disorder and PDP scales correlated significantly and positively ( $r=0.38$ for males, $r=0.34$ for females, both $p<0.001$ ). Partialling out PNMS did not significantly diminish these correlations (partial correlation after controlling for PNMS: $r=0.36$ for males, $r=0.32$ for females, both $p<0.001$ ).

Finally, because one item in the PNMS measure ("pregnancy problems") could be confounded with perinatal complications, which have been associated with autism and ADHD, analyses were rerun after removing this one item from the PNMS measure. The results were not significantly different: the effect of PNMS without the pregnancy problems item on PDP scores was significant for boys ( $p=0.005)$ but not girls $(p=0.446)$, and the effect of PNMS without the pregnancy problems item on ADHD scores was significant for both boys and girls ( $p=0.014$ and 0.028 , respectively).
Table 3 | Multivariate linear regression model for ADHD behavior scores at age 2 years.

\begin{tabular}{|c|c|c|c|c|}
\hline & \multicolumn{2}{|c|}{ Males } & \multicolumn{2}{|c|}{ Females } \\
\hline & $\beta$ & SE B & $\beta$ & SE B \\
\hline \multicolumn{5}{|l|}{ STEP 1: COVARIATES } \\
\hline Maternal age at conception & 0.01 & 0.02 & 0.01 & 0.02 \\
\hline $\begin{array}{l}\text { Mother did not complete } \\
\text { secondary school }\end{array}$ & 0.02 & 0.19 & 0.04 & 0.20 \\
\hline $\begin{array}{l}\text { Father not present } \\
\text { in family home }\end{array}$ & 0.01 & 0.29 & 0.02 & 0.28 \\
\hline Family income $<\$ A U D 24,000$ & -0.01 & 0.20 & 0.07 & 0.21 \\
\hline \multicolumn{5}{|c|}{ MATERNAL INTAKE DURING PREGNANCY } \\
\hline $\begin{array}{l}\text { Alcohol } \geq \text { several } \\
\text { times per week }\end{array}$ & 0.02 & 0.40 & -0.05 & 0.41 \\
\hline Smoking & $0.07^{*}$ & 0.28 & 0.05 & 0.27 \\
\hline \multicolumn{5}{|l|}{$11+$ cigarettes per day } \\
\hline Parity $=1$ & 0.06 & 0.21 & -0.02 & 0.23 \\
\hline Parity $>1$ & $-0.09^{*}$ & 0.25 & -0.07 & 0.26 \\
\hline Baby blues symptoms & $0.09^{*}$ & 0.03 & -0.03 & 0.03 \\
\hline Child's age at & $-0.08^{*}$ & 0.56 & 0.00 & 0.60 \\
\hline \multicolumn{5}{|l|}{2 year assessment } \\
\hline PDP score & $0.35^{* *}$ & 0.10 & $0.33^{* *}$ & 0.11 \\
\hline$R^{2}$ for Step 1 & \multicolumn{2}{|c|}{$0.17^{* *}$} & \multicolumn{2}{|c|}{$0.15^{* *}$} \\
\hline \multicolumn{5}{|l|}{ STEP 2: PREDICTORS } \\
\hline $\begin{array}{l}N \text { stress events } \\
\text { during pregnancy }\end{array}$ & $0.07^{*}$ & 0.11 & $0.10 * *$ & 0.12 \\
\hline$\Delta R^{2}$ for Step 2 & \multicolumn{2}{|c|}{$0.01^{*}$} & \multicolumn{2}{|c|}{$0.01 * *$} \\
\hline Change in $F_{\text {model }}$ & \multicolumn{2}{|c|}{$4.73^{*}$} & \multicolumn{2}{|c|}{$7.50^{* *}$} \\
\hline
\end{tabular}

$P D P$, pervasive developmental problems (autistic traits) subscale. ADHD, attention deficit hyperactivity subscale. ${ }^{*} p<0.05 ;{ }^{* *} p<0.01$.

\section{DISCUSSION}

The aim of this prospective investigation was to explore for the first time the association between PNMS and autistic traits and ADHD behaviors in 2-year-olds. PNMS was significantly associated with ADHD behaviors in both genders after controlling for autistic traits. PNMS was significantly associated with autistic traits after controlling for the effect of ADHD behaviors in boys only. Autistic traits and ADHD behaviors were moderately correlated in our sample, and partialling out the effect of PNMS did not significantly lower the correlation. These findings suggest that PNMS is independently associated with both autistic traits and ADHD behaviors. In terms of effect size, PNMS explained 1\% of the variance of both autistic traits and ADHD behaviors, after controlling for multiple covariates. Although small, this effect was significant for both scales (with the exception of females for autistic traits).

Although previous studies have shown an association between specific prenatal stressors (family discord, hurricanes) and retrospectively recalled stressors (stressful life events) with autism, this is the first study to use a prospective assessment of a broad array of common stressors as an indicator of PNMS, and to report an association with a broader quantitative measure of autistic traits in a preschool sample. In terms of the PNMS and ADHD literature, this study concurs with existing literature in showing a significant 
association between PNMS and ADHD behaviors, and it extends the literature by showing that this association still holds after controlling for a large number of covariates, including autistic traits, and that the association is significant in preschool children.

In terms of the covariates, it is notable that significant associations were observed between ADHD behaviors in 2-year-old boys and prenatal maternal smoking and postnatal maternal baby blues symptoms; findings that concur with some previous literature (e.g., Hay et al., 2003; D'Onofrio et al., 2008). A significant association was also observed between autistic traits in 2-year-old girls and postnatal maternal baby blues symptoms. The gender differences in these findings are intriguing but require replication in other samples.

The prospectively collected data, the large sample, and the statistical adjustment for a large number of covariates are clear strengths of this study. Several limitations of the current design should also be noted. Autistic traits and ADHD behaviors were based on maternal ratings. Correlated rater error would act to inflate the correlation between maternally rated PNMS and maternally rated autistic and ADHD behaviors in the offspring. However, parental assessment of problem behavior is a practical option for large preschool samples, and parents are familiar with behavior across time and a range of contexts. In terms of the measures, it was advantageous to employ scales from the CBCL, which have been widely used and assessed for reliability and validity (Achenbach and Rescorla, 2000). Nevertheless, the reliability, as assessed by Cronbach's $\alpha$, for the PDP scale was modest in the present sample. Error of measurement from these scales would act to decrease the phenotypic correlation between PNMS and offspring behavior, which would reduce the observable effect size of the association. As such, if anything this error of measurement acts to make the results more conservative.

The study did not include information on the mothers' subjective experience of the stressors. There is some evidence that objective measures of stress are better than subjective measures at predicting later child outcome (Laplante et al., 2008). Finally, the sample was subject to a modest degree of attrition bias, with socially disadvantaged mothers less likely to participate. While the loss of these participants may have affected the results of this study, computer simulations using data from the Avon Longitudinal Study of Parents and Children, have found that selective dropout in cohort studies only marginally affects regression coefficients, if participant selection occurs according to the predictor variable(s) (Wolke et al., 2009). Future studies that prospectively assess mothers' PNMS and their offspring's behavior could aim to use longer measures and observational (rather than maternal) assessments in order to avoid potential for correlated rater error between the two points of assessment.

What are the potential genetic and environmental causes underlying these associations? Stressful life events might be considered to be environmental variables. However, it is a well-established finding in behavior genetics that many "environmental" variables show genetic influence, the so-called "nature of nurture" (Plomin and Bergeman, 1991). It is possible that genes that influence to what degree mothers experience stress during pregnancy are shared with the genes that influence risk for developmental problems in offspring (who share $50 \%$ of their mother's DNA). A recent study that tried to disentangle the role of genetic and environmental influences on the relationship between PNMS and developmental problems in offspring employed a cross-fostering design - comparing ADHD behaviors in offspring whose prenatal environment was provided by a genetically related "biological" mother versus via an unrelated "non-biological" mother. The study found that ADHD behaviors in offspring of non-biological mothers did not show an association with PNMS (Rice et al., 2010). This suggests that the association between PNMS and ADHD behaviors in offspring may be due to inherited factors. No cross-fostering design has studied PNMS and autism or autistic traits.

The degree to which the mother's genes influence PNMS will depend on the nature of the stressor. For example, hurricanes and wars are likely to be stressors that occur independently of the mother's behavior and of her genotype, whereas the presence of family discord is likely to be partly correlated with the mother's genotype (this is analogous to life events being distinguished as to whether they are independent or not necessarily independent of disease onset, e.g., Brown and Birley, 1968). In the present study, we included stressors such as "death of a close friend" that, in most cases, are unlikely to be related to the mother's genotype, whereas "personal relationship problems" and "money problems" may be correlated with heritable components such as maternal temperament (gene-environment correlation). However, our measure of PNMS did not include enough items that might be deemed sufficiently independent of the mother's genotype to test the association separately for these types of stressful events. The mother's genotype will also affect the nature of the stress response, regardless of the type of stressor. Further research is needed; our tentative prediction is that the $1 \%$ variance that PNMS explained in ADHD behaviors/ autistic traits in preschool children in our study is due to both genetic and environmental factors.

Finally, gene-environment interaction studies could reveal further information about causality. In this context there could be both maternal genotype $\times$ environment interactions and child genotype $\times$ environment interactions. That is, the effects of PNMS on autistic or ADHD traits may differ depending on the mother's or the child's underlying genotypes (e.g., Wakschlag et al., 2010). In this vein, a recent study reported a significant gene-environment interaction between the catechol $\mathrm{O}$-methyltransferase (COMT) Val158Met polymorphism and maternal smoking during pregnancy that resulted in increased autistic-like stereotyped behavior in a sample of children with ADHD (Nijmeijer et al., 2010).

The effect size of the association (1\%) was notably smaller than that reported in two previous studies on the association between maternal prenatal state trait anxiety/stress and ADHD behaviors in middle childhood which reported effect sizes of 22-23\% (Van den Bergh and Marcoen, 2004; Rodriguez and Bohlin, 2005). The different effect sizes may be due to the different prenatal stress variables used: prenatal state trait anxiety versus common stressful life events (employed here), as well as the much larger number of confounding variables that were controlled for in the present study, including autistic traits, which are significantly associated with both PNMS and ADHD. For example, the effect size of the association found in our study was three times greater before all the confounding factors were controlled for. Therefore a study that does not control for these confounders will give inflated estimates of the degree of association. It seems likely that removing the effects of covariates will have 
removed variation explained by both genetic and environmental influences. An additional reason for the relatively small effect size compared to studies of older children is the reliability of measurement of ADHD behaviors and autistic traits in 2- to 3-year-olds. The literature on early screening for ASDs has shown that behaviors show a degree of fluctuation across the preschool period and reliable measurement can be challenging (Yirmiya and Charman, 2010). Both ASD and ADHD diagnoses are usually not confirmed until children are slightly older. As such, it might be that the effect size of the association between PNMS and offspring behaviors, in this case those characteristic of autism and $\mathrm{ADHD}$, gets larger as offspring develop and behaviors become more stable.

In conclusion, this study suggests that PNMS, in the form of typical stressful life events, such as divorce or a residential move, show a small but significant association with both autistic traits and ADHD behaviors independently, in offspring at age 2 years, after controlling for multiple antenatal, obstetric, postnatal, and sociodemographic covariates. The findings suggest that intervention that seeks to minimize the number of stressors that a woman

\section{REFERENCES}

Achenbach, T. M., Edelbrock, C., and Howell, C. T. (1987). Empirically based assessment of the behavioral/ emotional problems of 2- and 3-yearold children. J. Abnorm. Child Psychol. $15,629-650$.

Achenbach, T.M., and Rescorla, L. (2000). Manual for the ASEBA Preschool Forms and Profiles. Burlington, VT: Department of Psychiatry, University of Vermont.

American Psychiatric Association. (1994). Diagnostic and Statistical Manual of Mental Disorders, 4th Edn. Washington, DC: American Psychiatric Association.

Beversdorf, D. Q., Manning, S. E., Hillier, A., Anderson, S. L., Nordgren, R. E., Walters, S. E., Nagaraja, H. N., Cooley, W. C., Gaelic, S. E., and Bauman, M. L. (2005). Timing of prenatal stressors and autism. J. Autism Dev. Disord. 35, 471-478.

Beydoun, H., and Saftlas, A. F. (2008). Physical and mental health outcomes of prenatal maternal stress in human and animal studies: a review of recent evidence. Paediatr. Perinat. Epidemiol. 22, 438-466.

Blair, E. M., Liu, Y., de Klerk, N. H., and Lawrence, D. M. (2005). Optimal fetal growth for the Caucasian singleton and assessment of appropriateness of fetal growth: an analysis of a total population perinatal database. BMC Pediatr. 5, 13. doi: 10.1186/1471-2431-5-13

Boksa, P. (2010). Effects of prenatal infection on brain development and behavior: a review of findings from animal models. Brain Behav. Immun. 24, 881-897.

Brown, G. W., and Birley, J. L. T. (1968). Crises and life changes and the onset of schizophrenia. J. Health Soc. Behav. 9, 203-214.

Constantino, J. N., Hudziak, J. J., and Todd, R. D. (2003). Deficits in reciprocal social behavior in male twins: evidence for a genetically independent domain of psychopathology. J. Am. Acad. Child Adolesc. Psychiatry 42, 458-467.

D’Onofrio, B. M., Van Hulle, C. A., Waldman, I. D., Rodgers, J. L., Harden, K. P., Rathouz, P. J., and Lahey, B. B. (2008). Smoking during pregnancy and offspring externalizing problems: an exploration of genetic and environmental confounds. Dev. Psychopathol. 20, 139-164.

Grizenko, N., Shayan, Y. R., Polotskaia, A., Ter-Stepanian, M., and Joober, R. during pregnancy to symptom severity and response to treatment in children with ADHD. J. Psychiatry Neurosci. 33, 10-16.

Hay, D. F., Pawlby, S., Angold, A., Harold, G. T., and Sharp, D. (2003). Pathways to violence in the children of mothers who were depressed postpartum. Dev. Psychol. 39, 1083-1094.

Henshaw, C. (2003). Mood disturbance in the early puerperium: a review. Arch. Womens Ment. Health 6, S33-S42.

Kendall, G. E. (2003). Children in Families in Communities: A Modified Conceptual Framework and an Analytic Strategy for Identifying Patterns of Factors Associated with Developmental Health Outcomes in Childhood. Unpublished doctoral dissertation, The University of Western Australia, Perth, Australia. Maternity blues. I. Detection and measurement by questionnaire. $\mathrm{Br}$. J. Psychiatry 155, 356-362. (2008). Relation of maternal stress

Kennerley, H., and Gath, D. (1989).

experiences during pregnancy could have an effect to reduce the risk of the offspring developing autistic traits or ADHD-like behaviors. These results lay the foundations for future research using epigenetic, cross-fostering, and gene-environment interaction designs to identify the causal processes underlying these associations.

\section{ACKNOWLEDGMENTS}

The authors would like to acknowledge the National Health and Medical Research Council (NHMRC) for their long term contribution to funding the study over the last 20 years. Core Management of the Raine Study has been funded by the University of Western Australia (UWA), the UWA Faculty of Medicine, Dentistry and Health Sciences, the Raine Medical Research Foundation, the Telethon Institute for Child Health Research, and the Women's and Infants' Research Foundation. The 2-year follow-up was funded by the NHMRC and the Raine Medical Research Foundation. The authors are extremely grateful to the study participants and their families as well as the Raine Study team for cohort co-ordination and data collection.

Kinney, D. K., Miller, A. M., Crowley, D. J., Huang, E., and Gerber, E. (2008). Autism prevalence following prenatal exposure to hurricanes and tropical storms in Louisiana. J. Autism Dev. Disord. 38, 481-488.

Laplante, D. P., Brunet, A., Schmitz, N., Ciampi, A., and King, S. (2008). Project ice storm: prenatal maternal stress affects cognitive and linguistic functioning in $51 / 2$-year-old children. J. Am. Acad. Child Adolesc. Psychiatry 47, 1063-1072.

Laucht, M., Esser, G., Baving, L., Gerhold, M., Hoesch, I., Ihle, W., Steigleider, P., Stock, B., Stoehr, R. M., Weindrich, D., and Schmidt, M.H. (2000). Behavioral sequelae of perinatal insults and early family adversity at 8 years of age. J. Am. Acad. Child Adolesc. Psychiatry 39, 1229-1237.

Lee, C. Y., Chang, Y. Y., and Lung, F. W (2006). The marriage-related risk factors during maternal pregnancy in children with attention-deficit hyperactivity disorder. Child Care Health Dev. 32, 205-211.

Li,J., Vestergaard,M., Obel,C., Christensen, J., Precht, D. H., Lu, M., and Olsen, J. (2009).A nationwide study on the risk of autism after prenatal stress exposure to maternal bereavement. Pediatrics 123, 1102-1107.

McIntosh, D. E., Mulkins, R. S., and Dean, R. S. (1995). Utilization of maternal perinatal risk indicators in the differential diagnosis of ADHD and UADD children. Int. J. Neurosci. 81, 35-46.

Newnham, J.P., Evans, S. F., Michael, C.A., Stanley, F. J., and Landau, L. I. (1993). Effects of frequent ultrasound during pregnancy: a randomized controlled trial. Lancet 342, 887-891.
Nijmeijer, J.S., Hartman, C.A., Rommelse, N. N., Altink, M. E., Buschgens, C. J., Fliers, E.A., Franke, B., Minderaa, R. B., Ormel, J., Sergeant, J.A., Verhulst, F.C., Buitelaar, J. K., Hoekstra, P. J. (2010). Perinatal risk factors interacting with catechol $O$-methyltransferase and the serotonin transporter gene predict ASD symptoms in children with ADHD. J. Child Psychol. Psychiatry 51, 1242-1250.

O'Connor, T. G., Heron, J., Golding, J., Beveridge, M., and Glover, V. (2002). Maternal antenatal anxiety and children's behavioural/emotional problems at 4 years. Report from the Avon Longitudinal Study of Parents and Children. Br. J. Psychiatry 180, 502-508.

O'Connor, T. G., Heron, J., Golding, J., and Glover, V. (2003). Maternal antenatal anxiety and behavioural/emotional problems in children: a test of a programming hypothesis. J. Child Psychol. Psychiatry 44, 1025-1036.

Plomin, R., and Bergeman, C. S. (1991). The nature of nurture: genetic influence on "environmental" measures. Behav. Brain Sci. 14, 373-427.

Reiersen, A. M., Constantino, J. N., Grimmer, M., Martin, N. G., and Todd, R. D. (2008). Evidence for shared genetic influences on selfreported ADHD and autistic symptoms in young adult Australian twins. Twin Res. Hum. Genet. 11, 579-585.

Rice, F., Harold, G. T., Boivin, J., van den Bree, M., Hay, D. F., and Thapar, A. (2010). The links between prenatal stress and offspring development and psychopathology: disentangling environmental and inherited influences. Psychol. Med. 40, 335-345. 
Rice, F., Jones, I., and Thapar, A. (2007). The impact of gestational stress and prenatal growth on emotional problems in offspring: a review. Acta Psychiatr. Scand. 115, 171-183.

Robinson, M., Oddy, W. H., Li, J. H., Kendall, G.E., de Klerk, N.H., Silburn, S. R., Zubrick, S. R., Newnham, J. P., Stanley, F. J., and Mattes, E. (2008). Pre- and postnatal influences on preschool mental health: a largescale cohort study. J. Child Psychol. Psychiatry 49, 1118-1128.

Rodriguez, A., and Bohlin, G. (2005). Are maternal smoking and stress during pregnancy related to ADHD symptoms in children? J. Child Psychol. Psychiatry 46, 246-254.

Ronald, A., Edelson, L. R., Asherson, P., and Saudino, K. J. (2010). Exploring the relationship between autisticlike traits and ADHD behaviors in early childhood: findings from a community twin study of 2-Yearolds. J. Abnorm. Child. Psychol. 38, 185-196.

Ronald, A., Simonoff, E., Kuntsi, J., Asherson, P., and Plomin, R. (2008). Evidence for overlapping genetic influences on autistic and ADHD behaviours in a community twin sample. J. Child Psychol. Psychiatry 49, 535-542.

Sikora, D. M., Hall, T. A., Hartley, S. L., Gerrard-Morris, A. E., and Cagle, S. (2008). Does parent report of behavior differ across ADOS-G classifications: analysis of scores from the CBCL and GARS. J. Autism Dev. Disord. 38, 440-448.

Simonoff, E., Pickles, A., Charman, T., Chandler, S., Loucas, T., and Baird, G. (2008). Psychiatric disorders in children with autism spectrum disorders: prevalence, comorbidity, and associated factors in a population-derived sample. J. Am. Acad. Child Adolesc. Psychiatry 47, 921-929.

Talge, N. M., Neal, C., and Glover, V. (2007). Antenatal maternal stress and long-term effects on child neurodevelopment: how and why? J. Child Psychol. Psychiatry 48, 245-261.

Tennant, C., and Andrews, G. (1976). A scale to measure the stress of life events. Aust. N. Z. J. Psychiatry 10, 27-32.

Van den Bergh, B. R., and Marcoen, A. (2004). High antenatal maternal anxiety is related to ADHD symptoms, externalizing problems, and anxiety in 8- and 9-year-olds. Child Dev. 75, 1085-1097.
Van den Bergh, B. R., Mulder, E. J., Mennes, M., and Glover, V. (2005). Antenatal maternal anxiety and stress and the neurobehavioural development of the fetus and child: links and possible mechanisms. A review. Neurosci. Biobehav. Rev. 29, 237-258.

Wakschlag, L. S., Kistner, E. O., Pine, D. S., Biesecker, G., Pickett, K. E., Skol, A. D., Dukic, V., Blair, R. J., Leventhal, B. L., Cox, N. J., Burns, J. L., Kasza, K. E., Wright, R. J., and Cook, E. H. (2010). Interaction of prenatal exposure to cigarettes and MAOA genotype in pathways to youth antisocial behavior. Mol. Psychiatry 15, 928-937.

Ward, A. J. (1990). A comparison and analysis of the presence of family problems during pregnancy of mothers of "autistic" children and mothers of normal children. Child Psychiatry Hum. Dev. 20, 279-288.

Wolke, D., Waylen,A., Samara, M., Steer, C. Goodman, R., Ford, T., and Lamberts, K. (2009). Selective drop-out in longitudinal studies and non-biased prediction of behaviour disorders. $\mathrm{Br}$. J. Psychiatry 195, 249-256.

Yirmiya, N., and Charman, T. (2010). The prodrome of autism: early behavioral and biological signs, regression, peri- and post-natal development and genetics. J. Child Psychol. Psychiatry 51, 432-458.

Conflict of Interest Statement: The authors declare that the research was conducted in the absence of any commercial or financial relationships that could be construed as a potential conflict of interest.

Received: 28 September 2010; paper pending published: 16 October 2010; accepted: 25 November 2010; published online: 19 January 2011.

Citation: Ronald A, Pennell CE and Whitehouse AJO (2011) Prenatal maternal stress associated with ADHD and autistic traits in early childhood. Front. Psychology 1:223. doi: 10.3389/fpsyg.2010.00223

This article was submitted to Frontiers in Developmental Psychology, a specialty of Frontiers in Psychology.

Copyright (C) 2011 Ronald, Pennell and Whitehouse. This is an open-access article subject to an exclusive license agreement between the authors and Frontiers Media $S A$, which permits unrestricted use, distribution, and reproduction in any medium, provided the original authors and source are credited. 